\title{
$17 \beta$-Estradiol Potentiates Kainate-Induced Currents via Activation of the cAMP Cascade
}

\author{
Qin Gu and Robert L. Moss \\ Department of Physiology, University of Texas Southwestern Medical Center at Dallas, Dallas, Texas 75235
}

\begin{abstract}
Evidence for nongenomic actions of steroids is now coming from a variety of fields of steroid research. Mechanisms of steroid action are being studied with regard to the membrane receptors and the activation of second messengers. The present study investigated the mechanism for the rapid effect of estrogen on acutely dissociated hippocampal CA1 neurons by using the whole-cell, voltage-clamp recording. Under the perforated patch configuration, $17 \beta$-estradiol potentiated kainateinduced currents in $38 \%$ of tested neurons. The potentiation was stereospecific, rapid in onset, and reversible after the removal of the steroid. Dose-response curves show that the potentiation by $17 \beta$-estradiol was evident at a concentration as low as $10 \mathrm{~nm}$ and saturated at $10 \mu \mathrm{M} .17 \beta$-Estradiol did not affect the kinetics (i.e., affinity and cooperativity) and reversal potential of kainate-induced currents. This suggests that the potentiation did not result from direct interaction with kainate
\end{abstract}

receptors nor the activation of ion channels other than kainate receptor-channels. The potentiation by $17 \beta$-estradiol was similar to the enhancement of kainate-induced currents evoked by 8-bromo-cAMP, and was modulated by an inhibitor of phosphodiesterase (IBMX). The estrogen potentiation was blocked by a specific blocker of PKA (Rp-cAMPS). Under standard recording configuration, the effect was significantly affected by intracellular perfusing with GDP- $\beta-\mathrm{S}$ or GTP- $\gamma-\mathrm{S}$. The data suggest that the potentiation of kainate-induced currents by $17 \beta$-estradiol was likely a G-protein(s) coupled, cAMPdependent phosphorylation event. By involvement of this nongenomic mechanism, estrogen may play a role in the modulation of excitatory synaptic transmission in the hippocampus.

Key words: steroid hormone; modulator; non-NMDA receptor; inward current; PKA; G-protein; nongenomic
Estrogen acts on a number of different target organs that contain specific estrogen receptors, including the brain, to modulate a variety of physiological functions (Stumpf and Sar, 1978; McEwen, 1979, 1991; Maggi and Prerez, 1985). Functionally, the effects of estrogen range from rapid actions on membrane excitability and synaptic transmission to long-term actions on sexual differentiation, development and maturation of the brain, morphological properties of neurons, endocrine regulation, and initiation of reproductive behavior (Gould et al., 1990; Woolley and McEwen, 1992).

Two mechanisms have been proposed to characterize the actions of estrogen (Wehling, 1995). The first is the genomic mechanism of action that involves the diffusion or transport of estrogen across the membrane into the neuron, activation of specific intracellular receptors, and transcriptional regulation of particular genes that ultimately results in protein synthesis (Pfaff, 1980; Pfaff and Schwartz-Giblin, 1988; Carson-Jurica et al., 1990; Smith et al., 1993). In contrast, estrogen has also been found to produce short-term actions on the electrical properties of neurons and transmitter release. The rapid onset and time course of these effects suggest that they are distinct from the genomic mechanism of action and indicate that estrogen may act on membrane recep-

Received Jan. 5, 1996; revised Feb. 27, 1996; accepted March 8, 1996.

This work was supported hy Research Grant 1 RO1-MH 47418 from the National Institute of Mental Health, National Institutes of Health, awarded to R.L.M. We thank Carol Dudley for her comments and criticisms on this manuscript and Dr. Tina Thompson for her technical assistance. We also thank Drs. Susan Mumby and AI Gilman for their generous gift of purified GDP- $\beta-S$ and GTP $-\gamma-S$.

Correspondence should be addressed to Dr. Robert L. Moss, Department of Physiology, University of Texas Southwestern Medical Center at Dallas, 5323 Harry Hines Boulevard, Dallas, TX 75235-9040.

Copyright (1) 1996 Society for Neuroscience $0270-6474 / 96 / 163620-10 \$ 05.00 / 0$ tors or other cellular components to alter neuronal events ( $\mathrm{Na}$ bekura et al., 1986; Smith et al., 1987, 1989; Minami et al., 1990; Kelly et al., 1992; Majewska, 1992; Paul and Purdy, 1992). However, the mechanisms to account for the rapid actions of estrogen have remained clusive.

In hippocampus, $17 \beta$-estradiol initiated a rapid and reversible increase in the amplitude of glutamate and kainate-induced or Schaffer collateral-activated EPSPs in CA1 hippocampal neurons. These responses were blocked by a non-NMDA antagonist (Wong and Moss, 1991, 1992). In subsequent experiments using excised patch-clamp recording from CA1 neurons, $17 \beta$-estradiol did not affect the parameters of single channel activity induced by kainate, a non-NMDA agonist (Wong and Moss, 1994). Because excised membrane patches lack many important cytoplasmic cnzymes and regulatory cofactors, it is likely that the rapid action may require that certain intracellular components remain intact.

There is mounting evidence that estrogen may activate intracellular second messenger systems to modulate neuronal functions. Estrogen has been shown to change cyclic nucleotide levels in the cell (Gunaga et al., 1974; Weissman et al., 1975), and act on potassium channels via a second messenger system involving cAMP to modulate the membrane potential (Minami et al., 1990). Furthermore, estrogen can directly stimulate inositol trisphosphates (Favit et al., 1991; Smith, 1991). At the receptor level, estrogen can rapidly alter ligand-binding properties of several G-protein-coupled neurotransmitter receptors such as 5-HT (Bigeon and McEwen, 1982), norepinephrine (Inaba and Kamata, 1979), and $D_{2}$ dopamine receptors (Levesque and DiPaolo, 1988; Bazzett and Bender, 1994). Estrogen has also been shown to induce rapid pharmacodynamic changes of the $\mathrm{G}$-protein-coupled mechanism of another ligand, decreasing the potency of opioid 
agonists in opening inward-rectifying potassium channels (Lagrange et al., 1994). Moreover, estrogen directly potentiates potassium-stimulated dopamine release in rat nucleus accumbens (Thompson and Moss, 1994).

In the experiments described here we address the hypothesis that $17 \beta$-estradiol potentiates the kainate-induced current by the activation of a cAMP cascade. We show that $17 \beta$-estradiol potentiates the kainate-induced current and that this potentiation is mimicked by cAMP and blocked by $R p$-cAMPS. Administration of GDP- $\beta$-S suppresses, whereas GTP- $\gamma$-S prolongs, the potentiation by estrogen. The findings suggest the nongenomic action of estrogen on kainate-induced currents involves activation of a cAMP-dependent phosphorylation process.

\section{MATERIALS AND METHODS}

All animal experimentation was conducted in accordance with the $\mathrm{Na-}$ tional Institutes of Health Guidelines for the Care and Use of Laboratory Animals.

Preparation of acutely dissociated neurons. CA1 hippocampal pyramidal neurons were acutely dissociated using modified procedures of Kay and Wong (1986). Sprague-Dawley male and female rats from 2 to 4 weeks old were decapitated via a guillotinc. Hippocampi were removed from the brain and quickly blocked and placed in cold PIPES-saline solution (in mM): $\mathrm{NaCl}, 120 ; \mathrm{KCl}, 5.0 ; \mathrm{CaCl}_{2}, 1.0 ; \mathrm{MgCl}_{2}, 1.0 ; \mathrm{D}$-glucose, 25; PIPES, 20 ; pH 7.4. The blocked tissue was cut on a vibratome (Oxford) at $\sim 450$ $\mu \mathrm{m}$ thick while bathed in $4^{\circ} \mathrm{C}$ oxygenated PIPES-saline solution. The slices were placed on a black surface and punches were made in the CA1 area with a capillary tube. The punches were incubated at room temperature $\left(20-22^{\circ} \mathrm{C}\right.$ ) in PIPES-saline solution with $1.5 \mathrm{mg} / \mathrm{ml}$ protease (Sigma, St. Louis, MO). The incubation medium was stirred slowly and smoothly with $95 \% \mathrm{O}_{2} / 5 \% \mathrm{CO}_{2}$ blown at its surface. After $30-45 \mathrm{~min}$ of enzymatic digestion, punches were rinsed three times in oxygenated PIPES-saline and triturated with a fire-polished Pasteur pipette for mechanical dissociation. The cell suspension was then plated into the central concave area of a slide containing the standard extracellular solution (in mM): $\mathrm{NaCl}, 140 ; \mathrm{KCl}, 3.0 ; \mathrm{CaCl}_{2}, 2.0 ;$ IILPLS, 10; pll 7.3. All chemicals were obtained from Sigma.

Whole-cell, patch-clamp recordings. Whole-cell recordings were performed under voltage-clamp mode according to standard techniques (Hammil et al., 1981). Both conventional as well as perforated whole-cell, patch-clamp recordings were used in isolated CA1 hippocampal neurons. The dissociated neurons were $-30-40 \mu \mathrm{M}$ in diameter and were visualized with a Nikon inverted phase-contrast microscope equipped with Nomarski optics.

Whole-cell recording electrodes were pulled from borosilicated glass with a Sutter Flaming-Brown electrode puller and fire-polished with a CPM-2 coating/polishing microforge. The electrode resistance was typically $2-5 \mathrm{M} \Omega$ in bath solution. The standard internal solution for recording electrode consisted of the following (in $\mathrm{mM}$ ): $\mathrm{CsCl}, 140 ; \mathrm{NaCl}, 4.0$; EGTA, 10; HEPES, $10 ; \mathrm{CaCl}_{2}$, 1. The internal solution was adjusted to $\mathrm{pH} 7.3$ with $\mathrm{CsOH}$. For perforated whole-cell recording, the electrode was first submerged in standard internal solution for 3-5 sec. A small amount of solution would reach the tip by capilary action. Then additional standard internal solution containing $100 \mathrm{mg} / \mathrm{ml}$ nystatin was added to the electrode by backfilling the electrode.

After formation of a gigaohm $(>1 \mathrm{G} \Omega$ ) seal, the membrane was ruptured by a slight suction in the case of conventional whole-cell recording. In the case of the perforated whole-cell recording configuration, however, series resistance and cell capacitance from a capacitive transient current evoked by voltage pulses $(-10 \mathrm{mV}, 20 \mathrm{msec})$ were monitored after obtaining a giga-seal. During the development of nystatin perforation, the amplitude of the capacitive transient increased and the time constant of the transient decreased. Whole-cell currents evoked by $20 \mathrm{mV}$ vollage sleps (from -80 to $+80 \mathrm{mV}$ ) gradually became larger with time, the series resistance decreased to a stable minimal value $(<12 \mathrm{M} \Omega$ ), indicating the establishment of perforated patch recording. This usually occurred within $15-25 \mathrm{~min}$. 'The subsequent recordings were held for more than $45 \mathrm{~min}$. The holding potential was $-60 \mathrm{mV}$ in both configurations, except in the case of studying the current-voltage relations where the holding potential was varied from -100 to $+50 \mathrm{mV}$. Access resistance was compensated $(80 \%)$ electronically and monitored periodically.
Puffer electrode and chemical application. A seven-barrel pipette with a total diameter of $10 \mu \mathrm{M}$ was used to puff individual substances on the dendrite of the recorded dissociated CA1 hippocampal neuron. Ejection of each chemical could be made separately with a picospritzer unit (General Valve Corp.). Kainate, 17 $\beta$-estradiol, $17 \alpha$-estradiol, 8-bromocAMP, IBMX, $R p$-cyclic adenosine $3^{\prime}, 5^{\prime}$-monophosphothioate $(R p$ cAMPS), or 8-bromo-cGMP were assigned randomly to one of the seven barrels. To establish a dose-response curve, each barrel of the pipette was assigned with one of the different concentrations of $17 \beta$-estradiol (100 $\mathrm{pM}, 1 \mathrm{nM}, 10 \mathrm{nlM}, 100 \mathrm{~nm}, 1 \mu \mathrm{M}, 10 \mu \mathrm{M})$ and kainate $(100 \mu \mathrm{M})$, or with one of the different concentrations of kainate $(1 \mu \mathrm{M}, 10 \mu \mathrm{M}, 100 \mu \mathrm{M}, 1 \mathrm{~mm}, 10$ $\mathrm{mm}$ ) and $17 \beta$-estradiol (100 nM). All chcmicals were from Sigma, but $K p$-cAMPS was obtained from LC Laboratories. Kainate currents were induced by pulses of ejection ( $20 \mathrm{msec}, 0.1-1.0 \mathrm{psi}$ ) of kainate at the dendrite of CA1 neuron. The application was repeated once every $30 \mathrm{sec}$ and commenced immediately after the patch was ruptured. The effects of the different drugs on the kainate-induced currents were tested by extracellularly perfusing the cell for $3 \mathrm{~min}$. In some experiments, guanosine $5^{\prime}-O$-(2-thiodiphosphate) (GDP- $\beta$-S), GDP, GTP, or guanosine $5^{\prime}-O$ - $(3-$ thiotriphosphate) (GTP- $\gamma-S)$ was added to the standard internal solution and allowed to diffuse into the cell. These experiments were conducted under the standard whole-cell recording configuration, and an ATP regeneration system consisting of $4 \mathrm{mg}$ of Tris-ATP, $20 \mathrm{~mm}$ phosphocreatine, and $50 \mathrm{U} / \mathrm{ml}$ creatine phosphokinase (all from Sigma) was added to the internal solution to minimize the washout effect on kainate-induced currents.

Kainate was made as a concentrated stock solution and was diluted in standard extracellular bath solution before use at a concentration of 100 $\mu \mathrm{M}$. $17 \beta$-Estradiol or $17 \alpha$-estradiol was initially dissolved in DMSO and diluted with standard extracellular bath solution to one of the following concentrations: $100 \mathrm{pm}, 1 \mathrm{nM}, 10 \mathrm{nM}, 100 \mathrm{nM}, 1 \mu \mathrm{M}$ with the final DMSO concentration not exceeding $0.01 \%$.8-Bromo-cAMP and 8-bromo-cGMP were made up in a stock solution and frozen. Aliquots were diluted with standard extracellular bath solution immediately before use to concentrations of $500 \mu \mathrm{M}$ and $1 \mathrm{~mm}$. IBMX was added directly to the external solution for final concentration of $100 \mu \mathrm{M}$. Rp-cAMPS was stored in a sealed container at $-20^{\circ} \mathrm{C}$ and diluted in external bath solution immediately before use at $50 \mu \mathrm{M}$. GDP- $\beta$-S and GTP- $\gamma-S$ were stored in aliquots at $-70^{\circ} \mathrm{C}$ and diluted to $500 \mu \mathrm{M}$ with standard internal solution.

Data analysis. Whole-cell currents were recorded under voltage-clamp configuration with Adams/List EPC-9 amplifier and sampled at $2 \mathrm{kHz}$ and filtered at $2.3 \mathrm{kHz}$. Data were digitized and stored on an Atari Mega 4 computer. Analysis of whole-cell current records was performed with an Atari data analysis program. Peak currents were normalized as $I / I_{0}$, where $I$ represents the amplitude of kainate-induced currents at any testing time point and $I_{0}$ is the initial value at the beginning of the recording. Percentage change in kainate-induced currents was determined according to the formula $\left(I_{\mathrm{drug}} / I_{0}-1\right) 100 \%$, where $I_{\mathrm{d} u g}$ represcnts the peak amplitude of the kainate current in the presence of the test drug. Dose-response data were fitted with the logistic equation in the form $I_{\mathrm{dr}}$ $-I_{0}=\left[I_{\max }-I_{0}\right] /\left[1+\left(\mathrm{EC}_{50} / D\right)^{\mathrm{nH}}\right]$ for $17 \beta$-estradiol, and $I=I_{\text {mial }} /[1+$ $\left.\left(\mathrm{EC}_{50} / D\right)^{\mathrm{mI}}\right]$ for kainate, where $I_{\mathrm{max}}$ is the response to a saturating concentration of agonist, $\mathrm{EC}_{50}$ is the concentration that cvokes a halfmaximal response, and $\mathrm{nH}$ is the estimated Hill coefficient that describes the steepness of the curve. Fitting was performed with SIGMAPLOT (Jandel Scientific, Corte Madera, CA). Current-voltage data were obtained by subtraction of leak currents from currents recorded in the presence of agonists at each potential. All quantitative data are expressed as mean \pm SEM; $n$ indicates the number of cell tested. Statistical analysis was performed using the paired or unpaired Student's $t$ test. Results wero considered significant only for $p<0.05$.

\section{RESULTS}

\section{Kainate-induced currents}

Under the conventional whole-cell recording configuration, application of kainate $(100 \mu \mathrm{M})$ to the dendrites of CA1 hippocampal neurons initially evoked an inward current. The initial amplitude of kainate-induced current was $560 \pm 214 \mathrm{pA}(n=12)$. The amplitude declined by $50 \%$ within 20 min (Fig. $1 A, B$ ). This washout effect was apparently attributable to intracellular dialysis (Korn et al., 1991) and was similar to that previously reported for kainate and NMDA currents (MacDonald et al., 1989; Wang et 
Figure 1. Comparison of kainate-induced currents using conventional and perforated whole-cell patch recording techniques on acutely dissociated CAl hippocampal neurons. $A$, Two eclls were recorded under the conventional whole-cell recording configuration. A $20 \mathrm{msec}$ pressure application of kainate $(100 \mu \mathrm{M})$ to the dendrites of these CAl neurons evoked an inward current, the amplitude of which declined to $50 \%$ of its initial value within 20 min (open triangles). One cell (open circles) was tested with $17 \beta$-estradiol $(100 \mathrm{~nm})$. The application of $17 \beta$-estradiol (solid circles) significantly retarded the decline in the amplitude of kainate-induced currents. Also in $A$, the amplitude of kainate-induced currents, obtained using the perforated patch recording, was stable for a period of up to $25 \mathrm{~min}$ (open squares). Individual current traces recorded under the conventional whole-cell patch configuration in the absence $(B)$ and presence $(C)$ of $17 \beta$-estradiol, and under perforated whole-cell patch configuration $(D)$, are shown to the right of the graph.

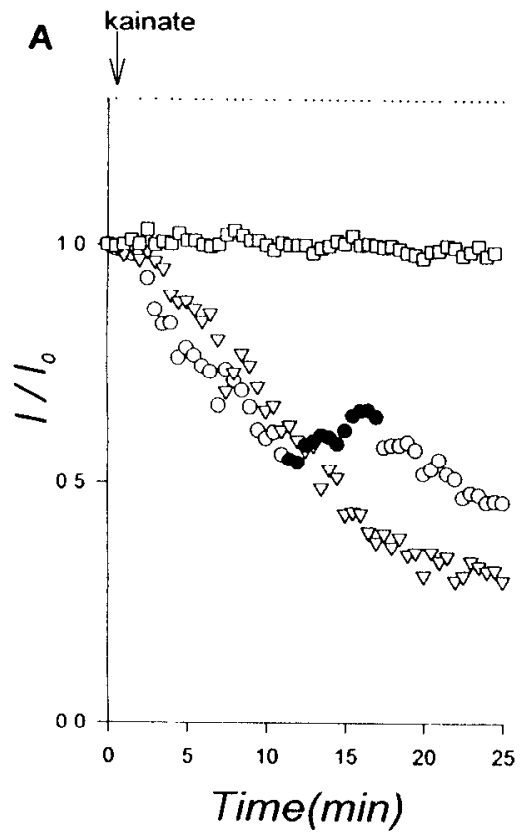

C

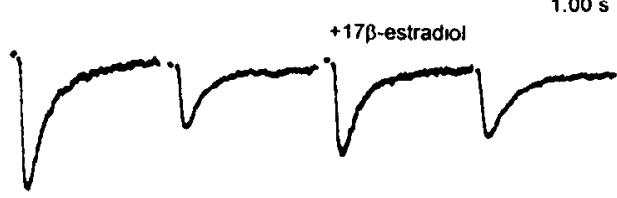

$200 \mathrm{pA}$ $1.00 \mathrm{~s}$ al., 1991). The application of $17 \beta$-estradiol $(100 \mathrm{~nm})$ significantly retarded the decline in kainate-induced current amplitude observed during washout (Fig. $1 A, C$ ). The effect of $17 \beta$-estradiol was observed in 3 out of 10 neurons tested, occurred within 5 min of application, and reversed within 3-5 min. To circumvent the washout of the kainate-induced currents, the perforated patch technique was used to record whole-cell currents. In this configuration, whole-cell recording can be done without diluting important substances from the cytoplasm, and plysiologically relevant mechanisms remain operational. Repeated application of kainate $(100 \mu \mathrm{M})$ onto a cell yielded responses with a peak value of $691 \pm$ $382 \mathrm{pA}(n=82)$. The amplitude rarely varied (within $\pm 10 \%)$ and was stable for a period of more than $45 \mathrm{~min}$ (Fig. 1A,D). All subsequent results were obtained under this perforated configuration except in the case where GTP- $\gamma$-S or GDP- $\beta$-S was included in the recording pipette.

\section{Potentiation of kainate-induced currents by $17 \beta$-estradiol}

The amplitude of kainate-induced currents was increased in the presence of $17 \beta$-estradiol $(100 \mathrm{nM}, 3 \mathrm{~min})$ by $45.86 \pm 4.1 \%$ of its original value ( 31 of 82 cells tested, $38 \%$ ). The potentiation was rapid in onset (within $3 \mathrm{~min}$ of application) and reversible. However, in the cells $(n=16)$ responsible to $17 \beta$-estradiol, the application of $17 \alpha$-estradiol (100 nM, $3 \mathrm{~min}$ ), an inactive isomer of $17 \beta$-estradiol, induced no obvious change in the kainate current (104.76 $\pm 5.81 \%$ compared with control as $100 \%$ ) (Fig. 2). It suggested that the potentiation was a stereospecific effect.

The potentiation by $17 \beta$-estradiol was evident at a concentration as low as $10 \mathrm{nM}$ and appeared to be saturated at $10 \mu \mathrm{M}(n=$ 5). The dose-response curve gave an $\mathrm{EC}_{50} 16.370 \pm 2.763 \mathrm{nM}$ and a $\mathrm{nH} 0.8878 \pm 0.0918$ (Fig. $3 A$ ). In the absence of kainate, $17 \beta$-estradiol alone had no obvious effect on membrane current (data not shown). Dose-response curves for various concentrations of kainate before $17 \beta$-estradiol ( $100 \mathrm{~nm}$ ) application show an $\mathrm{EC}_{50} 114.20 \pm 0.52 \mu \mathrm{M}$ and a $\mathrm{nH} 1.33 \pm 0.11$. The application of $17 \beta$-estradiol significantly $(p<0.02)$ increased the amplitude of kainate-induced currents $(56 \pm 5 \% ; n=5)$ at the tested kainate concentrations of $100 \mu \mathrm{M}, 1 \mathrm{~mm}$, and $10 \mu \mathrm{M} .17 \beta$-Estradiol had no cvident cffcct on the values of $\mathrm{EC}_{50}(102.96 \pm 0.92 \mu \mathrm{M})$ and $\mathrm{nH}$ $(1.15 \pm 0.16)$ (Fig. $3 B$ ).

Current-voltage curves show a nearly identical reversal potential $(0.350 \pm 0.3561 \mathrm{mV}$ compared with control $0.7625 \pm 0.1322$ $\mathrm{mV} ; n=6)$ and linearity. However, the slopes were significantly different $(2.220 \pm 1.090 \mathrm{nS}$ compared with control $1.6333 \pm$ $0.1291 \mathrm{nS} ; p<0.01 ; n=6)$. This result is consistent with the involvement of a nonspecific cationic conductance of kainateinduced currents. In the illustrated recording (Fig. 4), the conductance to kainate was increased from $1.8 \mathrm{nS}$ to $2.5 \mathrm{nS}$ by $17 \beta$-estradiol (100 nM).

\section{Mediation of cyclic nucleotide}

To investigate the mechanism underlying the potentiation of kainatcinduced currents by $17 \beta$-estradiol, possible modulatory agents including cyclic nuclentides (cAMP, cGMP) and IBMX were tested on the neurons responsive to $17 \beta$-estradiol. 8-Bromo-cAMP $(500 \mu \mathrm{M})$, a membrane-permeant and phosphodiesterase-resistant analog of cAMP, increased the amplitude of kainate-induced currents (39.60 $\pm 3.88 \% ; n=10)$, whereas 8-bromo-cGMP $(500 \mu \mathrm{M})$ had no effect on kainate-induced currents $(105.64 \pm 8.52 \%$ compared with control as $100 \% ; n=10)$. This finding suggests the possibility of specific effect of cAMP on kainate-induced currents. The enhancement evoked by 8-bromo-cAMP was similar to that of $17 \beta$-estradiol in the latency and magnitude of current increase (Fig. 5). IBMX, a membrane-permeant phosphodiesterase inhibitor, was tested to identify whether $17 \beta$-estradiol was exerting its effect via the cAMP cascade. IBMX $(100 \mu \mathrm{M})$ enhanced the effects of a subsaturating concentration (100 nM) of $17 \beta$-estradiol $(28.97 \pm 6.03 \% ; p<0.05 ; n$ $=4$ ) (Fig. 6A). IBMX applied alone had no obvious effect on membrane current or kainate-induced currents $(n=4$; data not shown). Furthermore, the presence of $17 \beta$-estradiol at its saturating concentration $(10 \mu \mathrm{M})$ occluded the enhancement induced by 8-bromo-cAMP (500 $\mu \mathrm{M})$ (Fig. $6 B$ ), even though both agents could potentiate the kainate-induced current when applied alone $(n=3)$. 


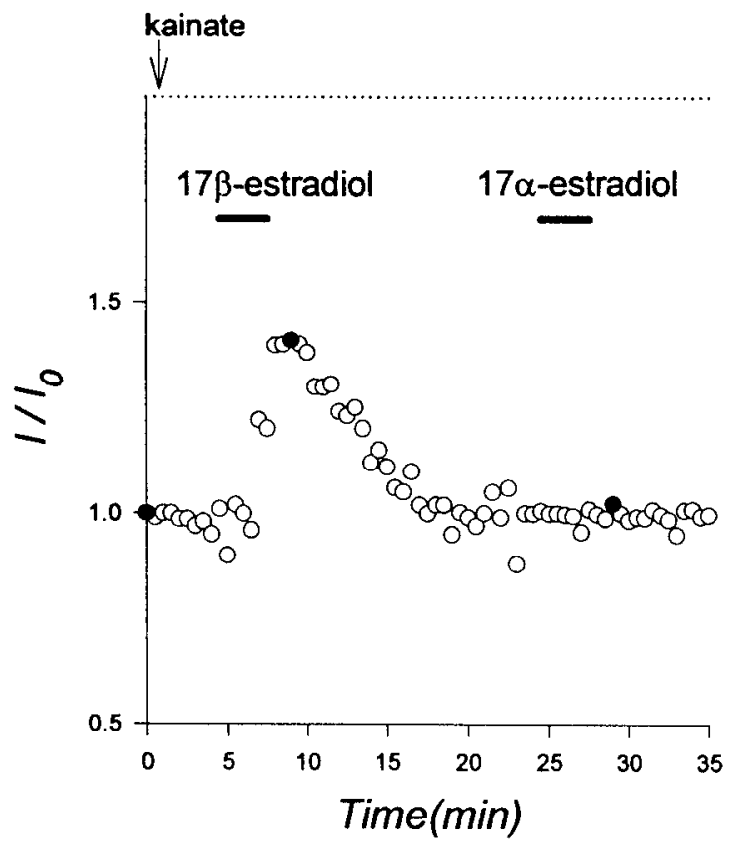

kainate $(100 \mu \mathrm{M})$

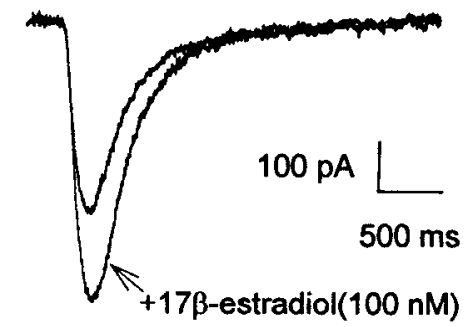

kainate $(100 \mu \mathrm{M})$

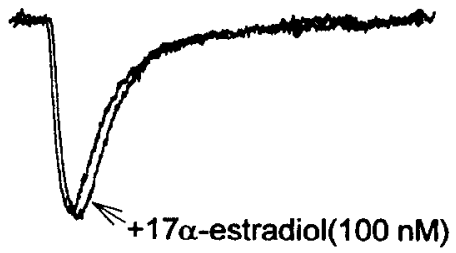

Figure 2. 17 $\beta$-Estradiol potentiated the kainate-induced current. The illustrated example shows the effects of $17 \beta$ - and $17 \alpha$-estradiol on kainate-induced currents recorded from an individual hippocampal neuron. The amplitude of kainate-induced currents was increased in the presence of $17 \beta$-estradiol $(100 \mathrm{nM})$ but not $17 \alpha-$ estradiol $(100 \mathrm{nM})$. The potentiation was rapid in onset (2-3 min from its application) and reversible after removal of the chemical. Actual current traces selected at specific time points (filled circles) are displayed to the right of the graph.

\section{Involvement of cAMP-dependent protein kinase and GTP-binding protein(s)}

In hippocampal CA1 neurons, the principle cellular target site of cAMP is the regulatory subunit of cAMP-dependent protein kinase (PKA). Because the results from the present study indicate that the effects of $17 \beta$-estradiol could be mediated by cAMP, inhibiting PKA should block the potentiation of $17 \beta$-estradiol on kainate currents. Experiments treating neurons with an inhibitor of PKA were consistent with this hypothesis. The administration of $R p$-cAMPS (50 $\mu \mathrm{M} ; n=5$ ), a particularly potent competitive

\section{B}

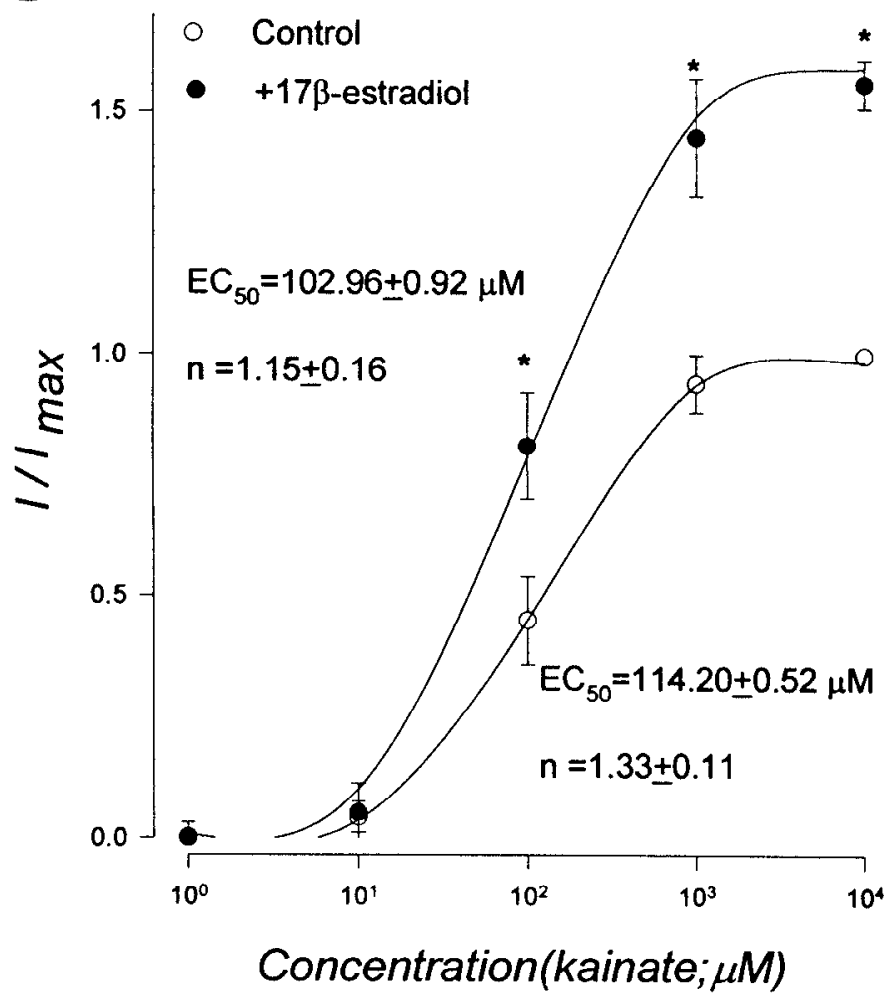

Figure 3. Potentiation of kainate-induced currents by $17 \beta$-estradiol was dose-dependent. $A$, The effect of $17 \beta$-estradiol was not evident at concentrations below $10 \mathrm{nM}$ and appears saturated at $10 \mu \mathrm{M}(n=5) . B$, Dose-response curves for various concentrations of kainate before $(O)$ and after $(\bullet) 17 \beta$-estradiol $(100 \mathrm{nM})$ application show that $17 \beta$-estradiol increased the amplitude of kainate-induced currents with no effect on the values of $\mathrm{EC}_{50}$ and $n_{\mathrm{H}}(n=5)$. 
kainate $(100 \mu \mathrm{M})$

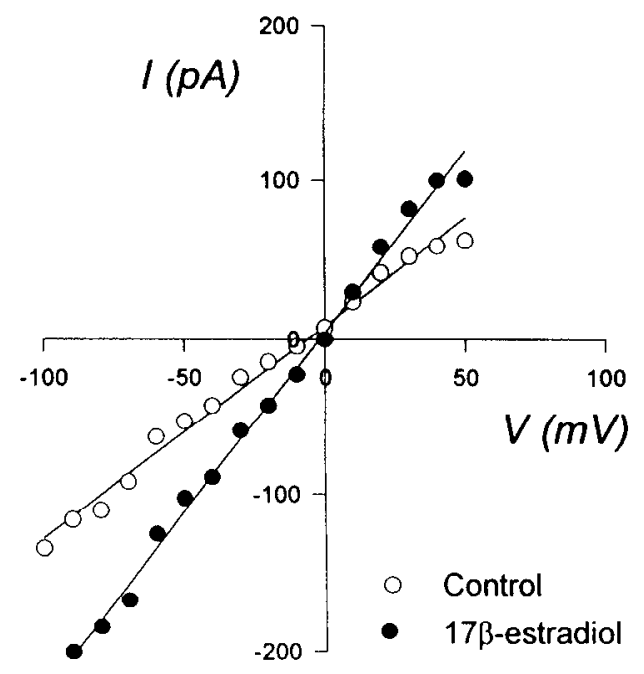

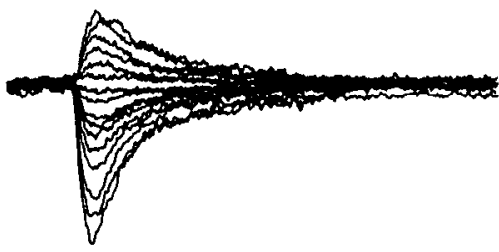

kainate $(100 \mu \mathrm{M})+17 \beta$-estradiol(100 $\mathrm{nM})$

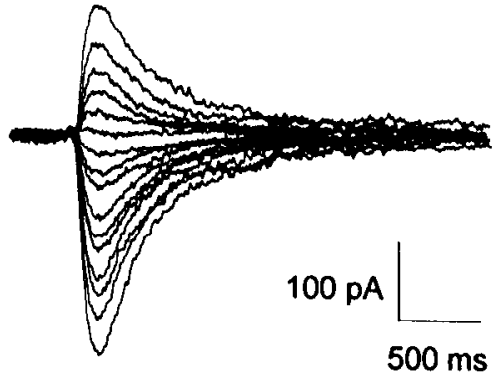

Figure 4. Current-voltage curves obtained in the absence (open circles) and presence (filled circles) of $17 \beta$-estradiol (100 nM). Both relationships are linear with a nearly identical reversal potential; however, the slopes were significantly different. $17 \beta$-Estradiol (100 nM) increased the conductance to kainate $(100 \mu \mathrm{M})$ from 1.8 lo $2.5 \mathrm{IIS}$, as determined from the slope of the current-voltage relation. Individual kainate-induced currents used to construct the plot are shown to the right of the graph. intracellular administration of $\operatorname{GDP}(500 \mu \mathrm{M})$ alone, as well as GTP (500 $\mu \mathrm{M}$; data not shown), had no effect on the kainateinduced currents $(n=3$; Fig. $8 B)$. The potentiation induced by $17 \beta$-estradiol was significantly $(p<0.001)$ prolonged in the presence of GTP- $\gamma$-S compared with control $(n=4$; Fig. $8 C)$. Intracellular diffusion of GDP- $\beta$-S or GTP- $\gamma-S$ alone caused no evident effect on membrane current or kainate-induced currents $(n=11$; data not shown).

\section{DISCUSSION}

The results indicate that $17 \beta$-estradiol potentiated kainateinduced currents in a subpopulation (38 and $37 \%$ from perforated
Figure 5. The enhancement of kainateinduced currents by cAMP, 8-bromocAMP $(500 \mu \mathrm{M})$ increased the amplitude of kainate-induced currents, whereas 8-bromo-cGMP $(500 \mu \mathrm{M})$ had no obvious effect on kainate-induced current. The enhancement evoked by 8-bromocAMP was similar to that of $17 \beta$ estradiol in the latency and magnitude. Sample current traces before and after 8-bromo-cAMP and 8-bromo-cGMP application are shown to the right of the graph.

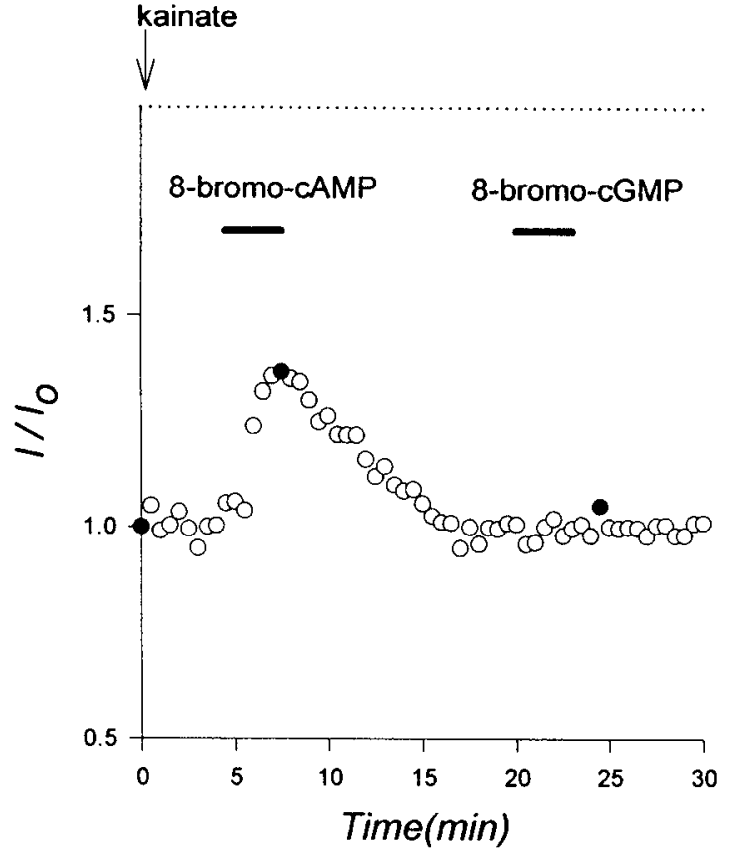

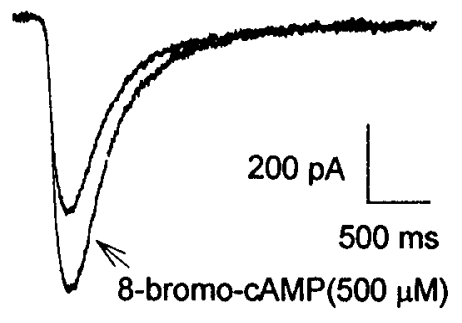

kainate $(100 \mu \mathrm{M})$

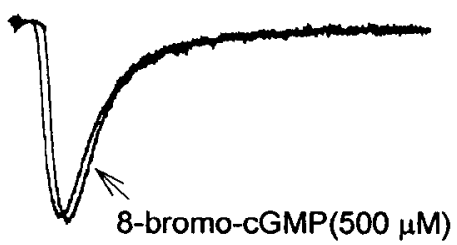




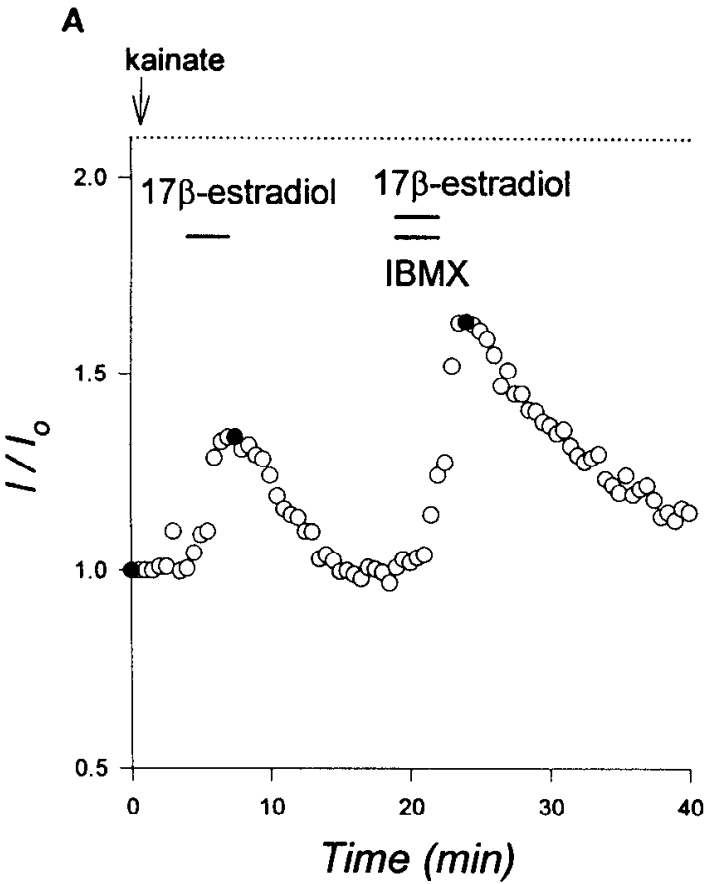

B

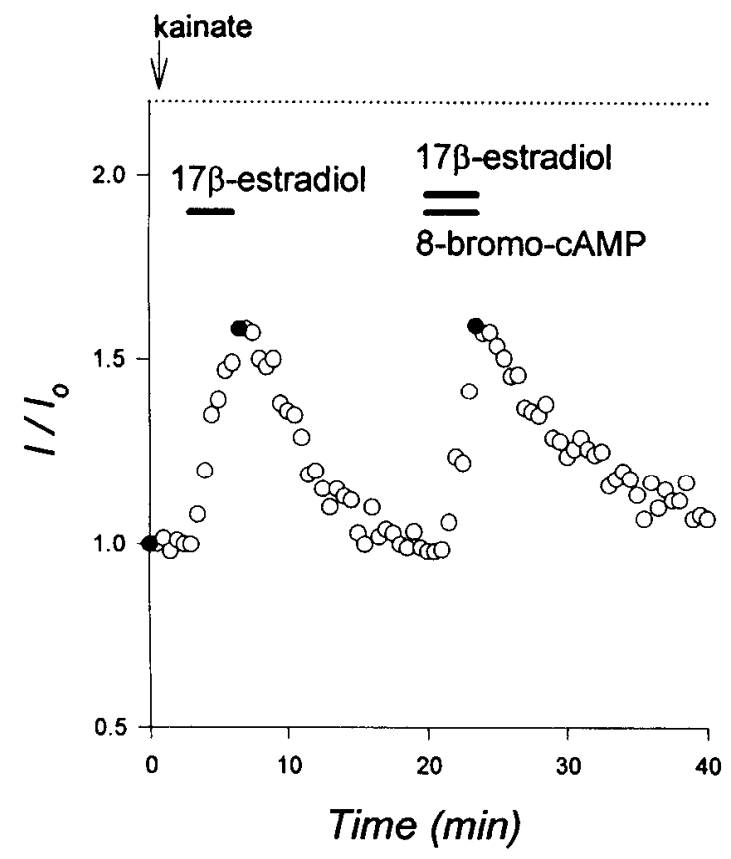

kainate $(100 \mu \mathrm{M})$

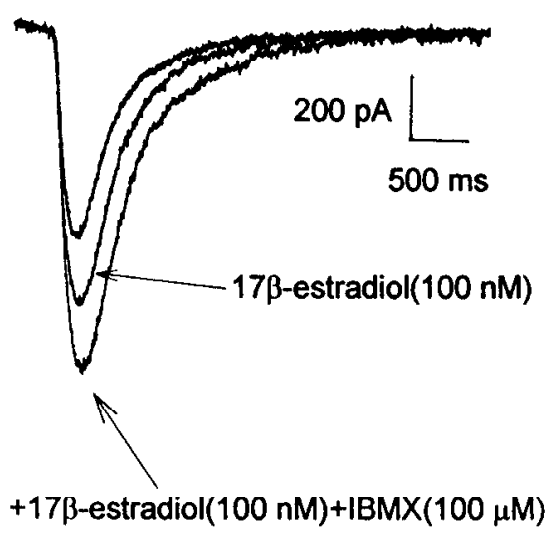

kainate $(100 \mu \mathrm{M})$
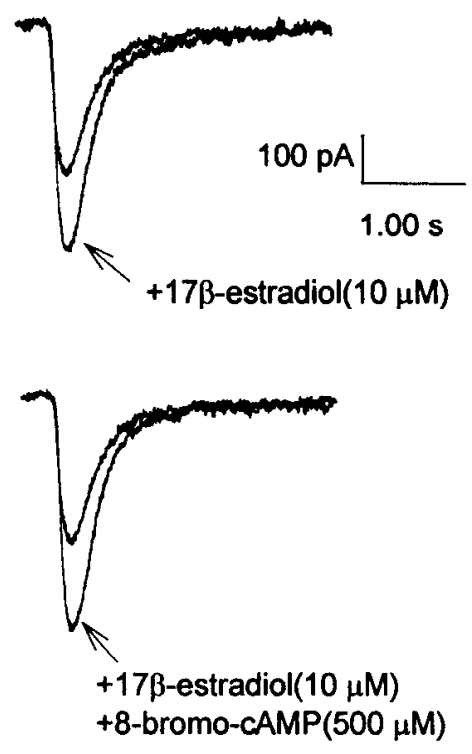

Figure 6. Potentiation of kainateinduced currents by $17 \beta$-estradiol was mediated by cAMP. $A$, Application of IBMX $(100 \mu \mathrm{M})$ enhanced the effect of $17 \beta$-estradiol $(100 \mathrm{~nm}) . B$, The presence of $17 \beta$-estradiol at its saturating concentration $(10 \mu \mathrm{M})$ almost occluded the enhancement induced by 8 -bromocAMP $(500 \mu \mathrm{M})$, even though both agents could potentiate the kainateinduced currents when applied alone (data not shown). Sample current traces selected at specific time points (filled circles) are shown to the right of the graphs. recording and standard recording, respectively) of acutely dissociated hippocampal CA1 neurons. The effects of $17 \beta$-estradiol were stereospecific, reversible, rapid in onset, and persisted for the duration of its application. Furthermore, the effects of $17 \beta$ estradiol on kainate-induced currents were mimicked by 8-bromocAMP and modulated by IBMX. The estrogen-induced potentiation was blocked by a specific blocker of PKA ( $R p$-cAMPS), suppressed by GDP- $\beta-\mathrm{S}$, and prolonged by GTP- $\gamma$-S. The data suggest that the potentiation of kainate-induced currents by $17 \beta$ estradiol appears to be mediated by a G-protein(s) coupled, cAMP-dependent phosphorylation of kainate receptors.

Despite previous electrophysiological evidence for modulation of glutamate receptors by estrogen, Wong and Moss reported that a single-channel analysis of both NMDA and non-NMDA receptors in the excised membrane patch failed to find evidence of direct glutamate receptor-channel modulation by estrogen, even though pregnenolone sulfate was shown to potentiate NMDA receptor-channel activity in the experiments (Wong and Moss, 1994). Their studies argued for an indirect interaction between estrogen and glutamate receptor ligands. However, there is more evidence from both non-neural and neural tissues that estrogen may directly activate the production of the cyclic nucleotide second messengers (Szego and Davis, 1967; Weissman et al., 1975; Mugge et al., 1993). Biochemical studies suggest that estrogen can 
Figure 7. Involvement of cAMPdependent protein kinase. $A$, The administration of Rp-cAMPS $(50 \mu \mathrm{M})$ completely eliminated the potentiation normally observed with the application of $17 \beta$-estradiol $(100 \mathrm{nM})$. Sample current traces selected at specific time points (filled circles) are shown to the right of the graph.

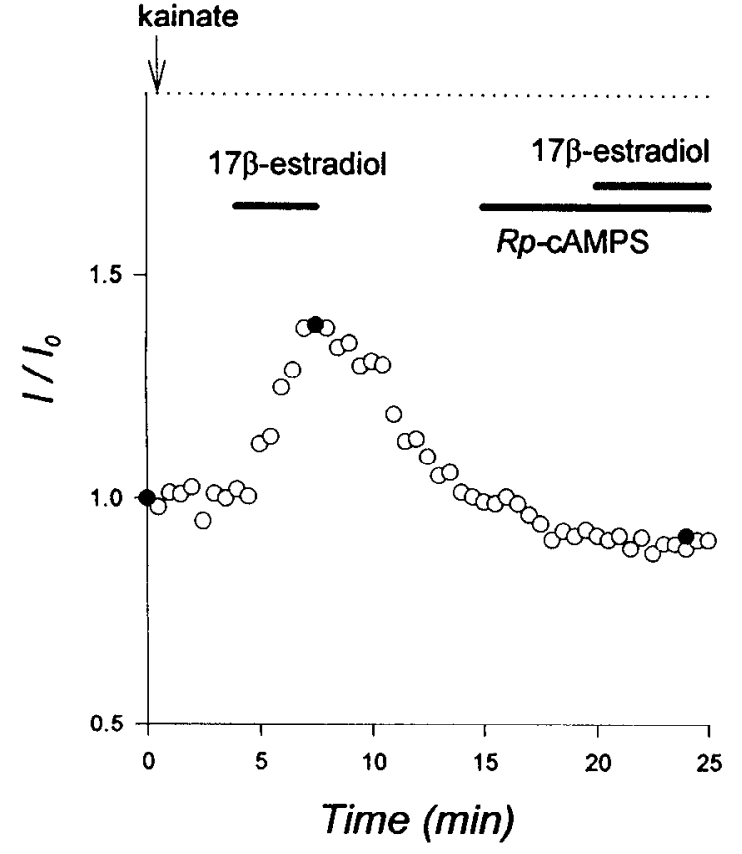

kainate $(100 \mu \mathrm{M})$
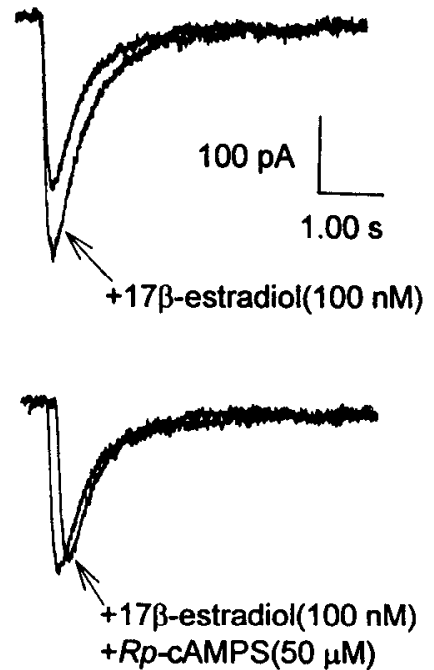

directly stimulate adenylate cyclase activity in uterine cells (Bergamini et al., 1985). Estrogen can acutely elevate the level of cAMP in hypothalamic neurons (Gunaga et al., 1974), and estrogen-induced depolarization associated with decreased potassium conductance is enhanced by a specific adenylate cyclase activator and a phosphodiesterase inhibitor (Minami et al., 1990). In the cerebellum, the estrogen-induced potentiation of excitatory responses to glutamate may be mediated by the inositol triphosphate second messenger system, as acute estrogen treatment increases quisqualate-stimulated phosphatidyl inositol in cerebellar neurons (Smith, 1991).

Several studies have suggested that brain second messenger systems, well known for altering nerve cell activity by modifying characteristics of voltage-gated channels (Kaczmarek and Levitan, 1987), also play a role in the modulation of ligand-gated ionotropic glutamate receptors (Wang et al., 1991, 1994; Blackstone et al., 1994; Lieberman and Mody, 1994). In cultured hippocampal neurons, the whole-cell current response to glutamate and kainate was enhanced by forskolin, an activator of adenylate cyclase, and the opening frequency and the mean open time of the nonNMDA-type glutamate receptor channel was increased by adenosine $3^{\prime}, 5^{\prime}$-monophosphate-dependent protein kinase (PKA) (Greengard et al., 1991). Based on the sequences of cloned subunits, most of the ligand-gated ionotropic glutamate receptors contain potential phosphorylation sites for $\mathrm{PKC}$ and $\mathrm{Ca}^{2+}$ / calmodulin-dependent protein kinase II (McGlade-McCulloh et al., 1993). The GluR6 subunit contains a consensus sequence for phosphorylation by PKA. Phosphorylation of kainate receptor complexes that contain the GluR6 subunit increases the glutamate- or kainate-induced responses (Raymond et al., 1993; Wang et al., 1993). The phenomenon of washout in the conventional whole-cell recording of kainate induced-currents resulted from the decreased ability of the neuron to maintain such physiologically relevant mechanisms, especially intracellular phosphorylation. Intracellular application of the catalytic subunit of PKA and cAMP prevented the rundown of kainate-induced currents (Wang et al., 1991). The retardatory effect of $17 \beta$-estradiol oc- curred with a short latency and appeared similar to that of PKA in preventing the washout of kainate-induced currents. This result suggested that the effect of $17 \beta$-estradiol likely involved the maintenance or activation of intracellular cAMP-dependent phosphorylation rather than a genomic mechanism.

An interesting feature of potentiation by $17 \beta$-estradiol on the kainate-induced current is the concentration of the steroid. In vivo, the gonads are the most likely source of estrogen and progestin. After release into the circulation, steroids can access most of the brain uniformly. At present there is no evidence for de novo synthesis of estrogens in the brain, however, the brain (glial cells and synaptic terminals) does contain a necessary enzyme (aromalase) for the conversion of circulating testosterone to $17 \beta$ estradiol. Pregnenolone and dehydroepiandrosterone are derived from cholesterol and are found in the brain at concentrations superior to those found in the blood on the order of $10 \mathrm{~nm}$ and 100 $\mathrm{nM}$ (Baulieu and Robel, 1991). In the present study, the effect of $17 \beta$-estradiol was dose-dependent; concentrations as low as $10 \mathrm{nM}$ potentiated the kainate-induced current. As $17 \beta$-estradiol was applied to the extracellular solution, the real concentration affecting the cell was lower than $10 \mathrm{~nm}$ and probably within the effective concentration range of other neurosteroids (Wong and Moss, 1992, 1994; ffrench-Mullen et al., 1994, 1995).

Dose-response curves show that the concentration of kainate required to evoke a half-maximal response was the same before and during the application of $17 \beta$-estradiol as were the calculated Hill slopes. This finding suggests that no substantial changes in either the apparent affinity or cooperativity of the response occurred during the application of $17 \beta$-estradiol. Analysis of current-voltage relationships before and after the introduction of $17 \beta$-estradiol showed that $17 \beta$-estradiol caused no obvious changes in the reversal potential of the kainate-induced current. This result suggests that the potentiation by $17 \beta$-estradiol did not result from activation of additional ionic conductance but was caused by increasing the conductance of the kainate receptorchannels. As the potentiation by $17 \beta$-estradiol was similar to the enhancement of kainate currents by 8 -bromo-cAMP both in the 


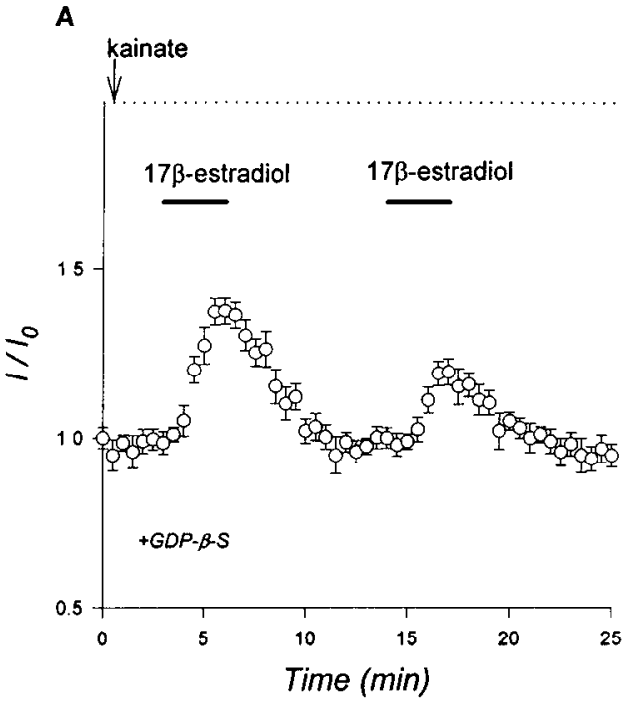

B

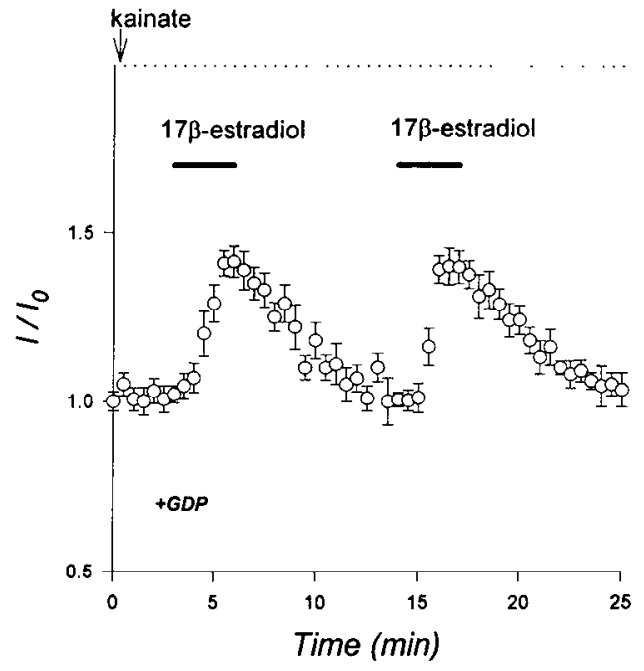

C

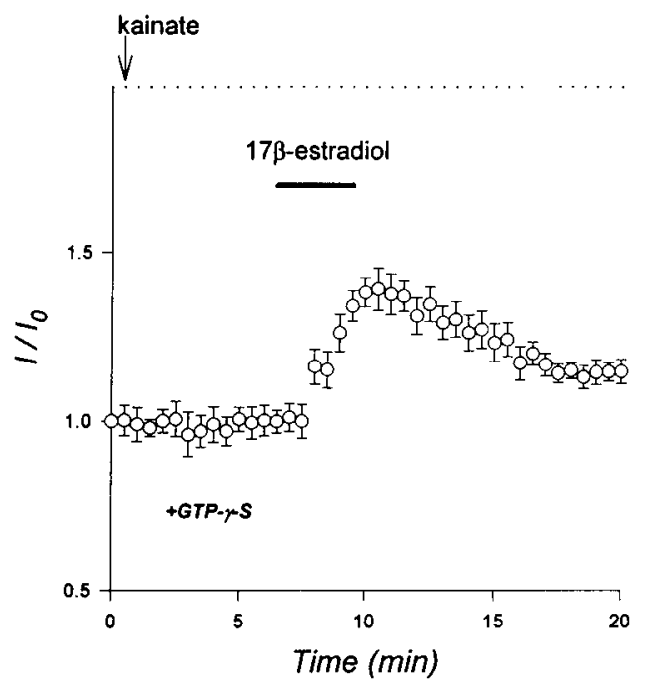

Figure 8. Effect of G-protein(s) on the $17 \beta$-estradiol potentiation of kainate-induced currents. Isolated hippocampal neurons were recorded under the conventional whole-cell configuration and dialyzed with GDP$\beta$-S $(500 \mu \mathrm{M})$, GDP alone, or GTP- $\gamma-\mathrm{S}(500 \mu \mathrm{M})$. As illustrated in $A$, the time course and degree, $17 \beta$-estradiol may have activated an intrinsic second messenger system rather than acted directly on the kainate receptors.

Evidence that $17 \beta$-estradiol acted through elevation of cAMP levels was obtained by application of IBMX, an agent that prolongs the lifeline of cAMP by inhibiting phosphodiesterase. IBMX enhanced the effect of $17 \beta$-estradiol. The ability of a saturating concentration of $17 \beta$-estradiol to occlude the modulation produced by 8-bromo-cAMP also argues for a shared pathway. The fact that a specific PKA inhibitor, $R p$-cAMPS, was able to block the effect of $17 \beta$-estradiol makes a more convincing case for the involvement of cAMP-dependent phosphorylation in the estrogenic modulation of kainate-induced currents.

Involvement of a $\mathrm{G}$-protein(s) in the $17 \beta$-estradiol potentiation of kainate-induced currents was addressed by including the nonhydrolyzable GTP analogs, GDP- $\beta-S$ and GTP- $\gamma$-S, in the recording electrode. GDP- $\beta-S$ and GTP- $\gamma-S$ compete with intracellular GTP for the binding site of G-protein at a subunit. GDP- $\beta$-S locks the GTPase cycle in an inactive status, and GTP- $\gamma-\mathrm{S}$ activales G-proteins irreversibly (Gilman, 1987; Hepler and Gilman, 1992). The estrogenic potentiation on kainate-induced currents was affected by intracellular perfusion of GDP- $\beta$-S or GTP- $\gamma-\mathrm{S}$, which suggests the action of $17 \beta$-estradiol was likely to be $G$-protein(s) coupled. The identity of the G-protein(s) and the specific subclass cannot be determined from the present data.

Recent reports indicate that some neurosteroids modulate voltage-gated calcium currents in hippocampal CAl neurons via a pertussis toxin-sensitive G-protein-coupled mechanism and the data suggests that the steroids can access their binding site from the extracellular surface (ffrench-Mullen et al., 1994, 1995). At the present time and to our knowledge, no evidence exists to support the notion of specific membrane binding sites for estrogen in hippocampus. Although high affinity membrane estrogen-binding sites have been identified from several specific brain regions, such as hypothalamus, cerebellum, and olfactory bulb (Zheng and Ramirez, 1994). In our recent preliminary experiments, $17 \beta$ estradiol conjugated with BSA had no observable effect on kainate-induced currents when applied to the outside of the cell (data not shown). Estrogen-BSA has been demonstrated to be biologically active (Lieberherr et al., 1993; Tesarik and Mendoza, 1995). Because estrogen is lipophilic and readily crosses the membrane and the conjugate (BSA) is membrane impermeable, this finding suggests that $17 \beta$-estradiol might have to cross the membrane to affect kainate-induced currents. a subpopulation of cytoplasmic steroid receptors that are not translocated to the nucleus has been described (Welshons and Judy, 1995). The estrogen could bind to these receptors and, theoretically, participate in rapid, nongenomic estrogen events.

In conclusion, the present results demonstrate that physiological levels of $17 \beta$-estradiol reversibly potentiate the amplitude of kainate-induced currents. This modulation is associated with a G-protein(s) coupled, cAMP dependent phosphorylation process. This potentiation of kainate-induced currents may participate in the regulation of glutamatergic transmission in hippocampus, where the glutamate receptors have been implicated in memory,

potentiation induced by $17 \beta$-estradiol shortly after membrane rupture was suppressed as GDP- $\beta$-S diffused into the cell ( $46 \pm 11 \% ; n=3$ ), whereas in $B$, intracellular perfusion with GDP alone had no effect on the kainateinduced currents $(n=3)$. $C$, The intracellular administration of GTP- $\gamma-\mathrm{S}$ prolonged the potentiation by $17 \beta$-estradiol $(n=4)$. 
epilepsy, excitotoxicity, and some neurodegenerative diseases (Collingridge and Lester, 1989; Meldrum and Garthwaite, 1990). Future studies are required to identify the binding sites on which $17 \beta$-estradiol exerts this nongenomic effect and to clarify the physiological significance of the enhancement of kainate-induced currents by $17 \beta$-estradiol in hippocampus.

\section{REFERENCES}

Baụlieu FE, Rohel P (1990) Neurosteroids: a new brain function? J Steroid Biochem Mol Biol 37:395-403.

Bazzett TJ, Bender JB (1994) Sex difference in the rapid and acute effects of cstrogen on striatal $\mathrm{D}_{2}$ dopamine receptor binding. Brain Rcs 637:163-172.

Bergamini CM, Pansini F, Bettocchi S, Segala V, Dallocchio F, Bagni G, Mollica $G$ (1985) Hormonal sensitivity of adenylate cyclase from human endometrium: modulation by estradiol. J Steroid Biochem $22: 299-303$.

Bigeon A, McEwen BS (1982) Modulation by estradiol of serotonin, receptors in brain. J Neurosci 2:199-205.

Blackstone C, Murphy TH, Moss SJ, Baraban JM, Huganir RL (1994) Cyclic AMP and synaptic activity-dependent phosphorylation of AMPA-preferring glutamatc receptors. J Neurosci 14:7585-7593.

Carson-Jurica MA, Schrader WT, O'Mallcy BW (1990) Stcroid receptor family: structure and functions. Endocr Rev 11:201-220.

Collingridge GL, Lester RAJ (1989) Excitatory amino acid receptors in vertebrate central nervous system. Pharmacol Rev 41:143-210.

Dostmann WRG, Taylor SS, Genieser H-H, Jasteroff B, Doskeland SO, Ogried D (1990) Probing the nucleotide binding sites of cAMPdependent protein kinase I and II with analogs of adenosine 3,5-cyclic phosphothioates. J Biol Chem 265:10484-10491.

Favit A, Fiore L, Nicoletti F, Canonico PL (1991) Estrogen modulates stimulation of inositol phospholipid hydrolysis by norepinephrine in rat brain slices. Brain Res 555:65-69.

french-Mullen JMH (1995) Contisol inhibition of calcium currents in guinea pig hippocampal CAl neurons via G-protein-coupled activation of protein kinase C. J Neurosci 15:903-911.

ffrench-Mullen JMH, Danks P, Spence KT (1994) Neurosteroids modulate calcium currents in hippocampal CA1 neurons via a pertussis toxin-sensitive G-protein-coupled mechanism. J Neurosci 14:1963-1977.

Gilman AG (1987) G proteins: transducers of receptor-generated sig nals. Annu Rev Biol Chem 56:615-649.

Gould E, Woolley CS, Frankfurt M, McEwen BS (1990) Gonadal steroids regulate dendritic spine density in hippocampal pyramidal cells in adulthood. J Neurosci 10:1286-1291.

Greengard P, Jen J, Nairn AC, Stevens CF (1991) Enhancement of the glutamate response by cAMP-dependent protein kinase in hippocampal neurons. Science 253:1135-1138.

Gunaga KP, Kawano A, Moenon KMJ (1974) In vivo effect of estradiol benzoate on the accumulation of adenosine $3^{\prime}, 5^{\prime}$-cyclic monophosphate in the rat hypothalamus. Neuroendocrinology 16:273-281.

Hammil OP, Marty A, Neher E, Sakmann B, Sigwoth FJ (1981) Improved patch-clamp techniques for high resolution current recording from cells and cell-free membrane patches. Pflügers Arch 391:85-100. Hepler JR, Gilman AG (1992) G-Proteins. Trends Biol Sci 17:383-387.

Inaba M, Kamata K (1979) Effect of estradiol-17 $\beta$ and other steroids on noradrenaline and dopamine binding to synaptic membrane fragments of rat brain. J Stcroid Biochem 11:1491-1497.

Kaczmarek LK, Levitan IB (1987) Neuromodulation. New York: Oxford UP.

Kay AR, Wong RKS (1986) Isolation of neurons suitable for patchclamping from adult mammalian central nervous systems. J Neurosci Methods 16:227-238.

Kelly MJ, Loose MD, Ronnekleiv OK (1992) Estrogen suppresses $\mu$-opioid- and $\mathrm{GABA}_{13}$-mediated hyperpolarization of hypothalamic arcuate neurons. J Neurosci 12:2745-2750.

Korn SJ, Marty A, Connor JA, Horn R (1991) Perforated patch recording. Methods Neurosci 4:356-373.

Lagrange AH, Ronnekleiv OK, Kelly MJ (1994) The potency of $\mu$-opioid hyperpolarization of hypothalamic arcuate neurons is rapidly attenuated by $17 \beta$-estradiol. J Neurosci 14:6196-6204.
Levesque D, DiPaolo T (1988) Rapid conversion of high into low striatal $\mathrm{D}_{2}$-dopamine receptor agonist binding states after an acute physiological dose of $17 \beta$-estradiol. Neurosci Lett 88:113-118.

Lieberherr M, Grosse B, Kachkache M, Balsan S (1993) Cell signaling and estrogens in female rat osteoblasts: a possible involvement of unconventional nonnuclear receptors. J Bone Mineral Res 11:1365-1376.

Lieberman DN, Mody I (1994) Regulation of NMDA channel function by endogenous $\mathrm{Ca}^{2+}$-dependent phosphatase. Nature 369:235-239.

MacDonald JF, Mody I, Salter MW (1989) Regulation of $N$-methyl-Daspartate receptors revealed by intracellular dialysis of murine ncurons in culture. J Physiol (Lond) 414:17-34.

Maggi A, Perez J (1985) Role of female gonadal hormones in the CNS: clinical and experimental aspects. Life Sci 37:893-906.

Majewska MD (1992) Neurosteroids: endogenous bimodal modulators on the $\mathrm{GABA}_{\mathrm{A}}$ receptor. Mechanisms of action and physiological significance. Prog Neurobiol 38:379-395.

McEwen BS (1979) Steroid hormone interactions with the brain: cellular and molecular aspects. Rev Neurosci 4:1-30.

McEwen BS (1991) Non-genomic and genomic effects of steroids on neural activity. Trends Pharmacol Sci 12:141-147.

McGlade-McCulloh E, Yamamoto H, Ten SE, Brickey DA, Soderling TR (1993) Phosphorylation and regulation of glutamate receptors by calcium/calmodulin-dependent protein kinase II. Nature 362:640-643.

Meldrum B, Garthwaite J (1990) Excitatory amino acid neurotoxicity and neurodegenerative discase. Trends Pharmacol Sci 11:379-387.

Minami T, Oomura Y, Nabekura J, Fukuda A (1990) 17B-Estradiol depolarization of hypothalamic neurons is mediated by cyclic AMP Brain Res 519:301-307

Mugge A, Riedel M, Barton M, Lichthen PR (1993) Endotheliumindependent relaxation of human coronary arteries by $17 \beta$-estradiol in vitro. Cardiovasc Res 27:1939-1942.

Nabekura J, Oomura Y, Minami T, Fukuda A (1986) Mechanism of the rapid effect of $17 \beta$-estradiol on medial amygdala neurons. Science 233:226-228

Paul SM, Purdy RH (1992) Neuroactive steroids. FASEB J 6:2311-2322

Pfaff DW (1980) Estrogen and brain function. Neural andalysis of hormone-controlled mammalian reproductive behavior. New York: Springer.

Pfatt DW, Schwartz-Giblin S (1988) Cellular mechanisms of female reproductive behavior: the physiology of reproduction. New York: Raven.

Raymond LA, Blackstone CD, Huganir RL (1993) Phosphorylation and modulation of recombinant GluR6 glutamate receptors by cAMP. dependent protein kinase. Nature 361:637-641.

Smith CL, Conneely OM, O'Malley BW (1993) Modulation of the ligand-independent activation of the human estrogen receptor by hor mone and antihormone. Proc Natl Acad Sci USA 90:6120-6124.

Smith SS (1989) Estrugen administration increases neuronal responses to excitatory amino acids as a long-term effect. Brain Res 503:354-357.

Smith SS (1991) The effects of estrogen and progesterone on GABA and glutamate responses at extra hypothalamic sites: neurosteroid and brain function. Fidia Res Found Symp Ser 18:87-94.

Smith SS, Waterhouse BD, Woodward DJ (1987) Sex steroid effects on extra hypothalamic CNS. I. Estrogen augments neuronal responsiveness to iontophoretically applied glutamate in the cerebellum. Brain Res 122:40-50.

Stumpf WE, Sar M (1978) Steroid hormone target sites in the brain: the differential distribution of estrogen, progestin, androgen and glucocorticosteroid. J Steroid Biochem 7:1163-1170.

Szego CM, Davis JS (1967) Adenosine 3',5'-monophosphate in rat uterus: acute elevation by estrogen. Proc Natl Acad Sci USA 58:1711-1718.

Tesarik J, Mendoza C (1995) Nongenomic effects of $17 \beta$-estradiol on maturing human oocytes: relationship to oocytes developmental potential. J Clin Endocrinol Metab 60:1438-1443.

Thompson TL, Moss RL (1994) Estrogen regulation of dopamine release in the nucleus accumbens: genomic-and nongenomic-mcdiated effects. J Neurochem 62:1750-1756.

Wang LY, Salter MW, MacDonald JF (1991) Regulation of kainate receptors by cAMP-dependent protein kinase and phosphatases. Science 253:1132-1135.

Wang LY, Taverna FA, Huang XP, MacDonald JF, Hampson DR (1993) Phosphorylation and modulation of a kainate receptor (GluR6) by cAMP-dependent protein kinase. Science 259:1173-1175. 
Wang LY, Orser BA, Brautlgan DL, MacDonald JF (1994) Regulation of NMDA receptors in cultured hippocampal neurons by protein phosphatases 1 and 2A. Nature 369:230-232.

Wehling M (1995) Looking beyond the dogma of genomic steroid action: insights and facts of the 1990's. J Mod Med 73:439-447.

Weissman BA, Daly JW, Skolnick P (1975) Diethylstilbestrol-elicited accumulation of cyclic AMP in incubated rat hypothalamus. Endocrinology 97:1559-1556.

Welshons WV, Judy M (1995) Nuclear vs Translocation steroid receptor models and the excluded middle. Endocrine 3:1-4.

Wong M, Moss RL (1991) Electrophysiological evidence for a rapid membrane action of the gonadal steroid, $17 \beta$-estradiol, on CA1 pyramidal neurons of the rat hippocampus. Brain Res 543:148-152.
Wong M, Moss RL (1992) Long-term and short-term electrophysiological effects of estrogen on the synaptic properties of hippocampal CA1 neurons. J Neurosci 12:3217-3225.

Wong M, Moss RL (1994) Patch-clamp analysis of direct steroidal modulation of glutamate receptor-channels. J Neuroendocrinol 6:347-355.

Woolley CS, McEwen BS (1992) Estradiol mediates fluctuations in hippocampal synapse density during the estrous cycle in the adult rate. J Neurosci 12:2549-2554.

Zheng J, Ramirez VD (1994) Purification and identification of estrogenbinding proteins from neuronal membranes of female rat brain. Soc Neurosci Abstr 20:95. 